\title{
Cycle Time
}

\section{Michael Moon}

is President of GISTICS and a lecturer and leading authority on digital asset management, automation of marketing services and multichannel brands. He has delivered more than 300 keynotes, presentations, executive seminars, workshops, and web-based seminars around the world. His book Firebrands: Building Brand Loyalty in the Internet Age has been published in 13 different languages. He also conducts primary research through surveys and one-to-one interviews. Michael and his team advise international-brand corporations on multichannel strategies for brand management and digital asset management, including Amway, Boeing, Disney, Frank Russell Company, Gap, General Motors, FCB, Hallmark, Hasbro, Leo Burnett, Nokia, Sanoma WSOY, TeliaSonera, Thomson Corporation, VF Corp and Warner Bros.

\section{METATAGGING MARCOM ASSETS}

Who has principal responsibility for tagging digital assets with metadata? When in the lifecycle of digital assets should you apply the core set of metadata? What can you do to reduce the cost and speed the process of "metatagging" (applying metadata to files)?

In issue 1(4) of this Journal we examined many facets of metadata, or "descriptive data about files." We framed digital asset management (DAM) as primarily concerned with the creation and management of transformation metadata and how these metadata enable extensive reuse of source files or digital assets. Transformational use of files distinguishes DAM from content management that emphasizes the management and distribution of dumb, use as-is files.

In issue 1(5) we examined how digital assets come into being, evolve and eventually retire, introducing the idea of Michael Moon CEO, GISTICS Inc. 4171 Piedmont Avenue Suite 210

Oakland, CA 94611, USA Tel: +1510 4509999 Email: moon@gistics.com a digital asset lifecycle. In particular, we discussed the lifecycle for marcom assets — the digital media files typically created by advertising agencies and creative partners.
Now let's dive a bit deeper into the marcom asset lifecycle, and address the introductory questions of today's paper.

As a general rule, the owner of the asset has responsibility for defining and managing the metadata schema - the technical specifications for the categories and sub-categories of metadata, including hierarchy of search terms that librarians call taxonomies.

If you find yourself just starting out with DAM, we cannot overstate the importance of hiring a good metadata architect to establish your metadata schema and keywords.

Nor can we overstate the importance of a fully documented workflow with checklists and daily reporting for cataloging an asset. This will not only enable you to ensure quality input (and therefore output), a documented workflow will reveal the time and cost of cataloging one asset. You will find, if you have not already, that fact-based knowledge of cataloging costs enables you to hire additional staff, outsource it with certainty, or charge-back a department or user group that wants access to a particular asset.

Our research of more than 1,000 operational DAM systems reveals 
diverse metatagging approaches, ranging from a centralized librarian or archivist function to a decentralized activity with hundreds of marcom and agency staff tagging their assets. Generally, a centralized approach remains the best overall approach as measured by quality, consistency and searchability across a global repository. This acknowledges the fact that most asset creators do not understand metadata, nor do they care or want to learn about it. In their minds, they create, not catalog.

Advanced DAMsters (from

DAMsterdam, of course!) have long practiced the creation of metadata containers, using placeholder proxies to anchor location in a DAM system for real assets that will come later. In this way, a librarian or project manager prepopulates a DAM repository record with known metadata, such as job number, rights, clearances, themes and high-level descriptions of contents (eg young man using Norelco shaver in bathroom). Thus, when agency or photographer uploads the real photo, they avoid having to input much of the metadata, and users have access to the latest material.

We have also encountered advanced DAMsters that ask the creative types to simply drag a Photoshop or Illustrator file into a nested set of desktop folders; an AppleScript then automatically appends the appropriate metadata to the file. In this way, asset creators need only drop their final work into five or so folders within folders, and hey presto accurate-every-time metadata append to the file.

Figure 1 depicts another crucial aspect of metatagging. The real process-systems fix to metatagging starts with how the marcom group buys creative services and marketing content. Quite simply, marcom needs to specify in each of its agency contracts and contractor's statements of work, "We will pay you when you have uploaded your files to our DAM system, and cataloged them with the specified metadata and specified dimensions, formats and color models."

We also know of several ad agencies that have taken a leadership role in metatagging, taking on the role of

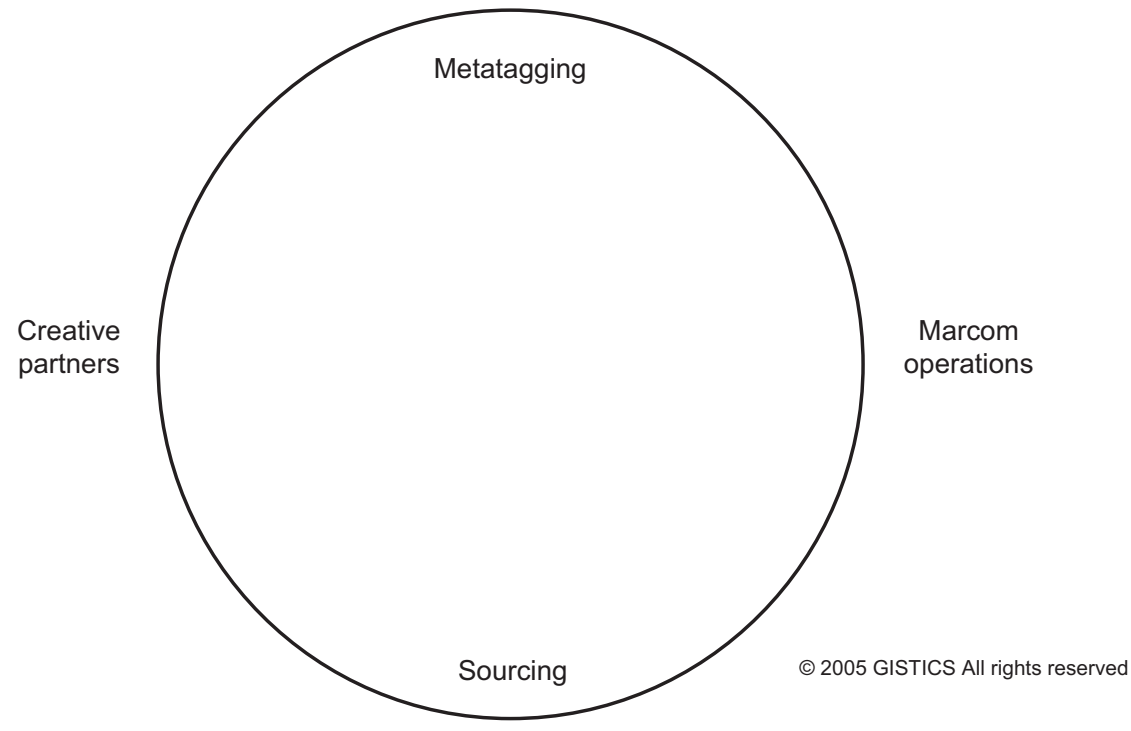

Figure 1 A crucial aspect of metatagging 
metadata architects and catalogers. In this arrangement, the client outsourced metatagging to their agency, paying the agency for one full-time librarian to wrangle assets. Once collected, processed and metatagged, the agency pushes XML-tagged assets into their clients DAM as well as their client's marketing services portals.

In summary, metatagging should start at the earliest point in the digital asset lifecycle. Metatagging requires a preestablished metadata schema. We recommend the creation of metadata containers with throw-away proxies and an automated search-and-replace procedure. If possible, we recommend that you restructure your agency and creative partner contracts, pushing to them the timely and accurate metatagging of their work products. Your fact-based accounting of the time it takes to upload and catalog an asset provides the baseline for negotiation, and which party will take on cataloging costs as incremental charge or as cost of doing business.

Marcom can speed the metatagging process by explicit terms in sourcing agreements with creative partners. This will require that marcom establish and maintain the metadata framework, and verify compliance of creative partners. 